\title{
Repurposing Quaternary Ammonium Compounds as Potential Treatments for COVID-19
}

\author{
Nancy Baker ${ }^{\prime}$ - Antony J. Williams ${ }^{2}$ - Alexander Tropsha ${ }^{3} \cdot$ Sean Ekins ${ }^{4,5}$ (D)
}

Received: 6 May 2020 / Accepted: 18 May 2020 / Published online: 25 May 2020

(C) Springer Science+Business Media, LLC, part of Springer Nature 2020

\begin{abstract}
The COVID-19 pandemic has highlighted an important role for drug repurposing. Quaternary ammonium compounds such as ammonium chloride, cetylpyridinium and miramistin represent widely accessible antiseptic molecules with well-known broad-spectrum antiviral activities and represent a repurposing opportunity as therapeutics against SARS-CoV-2.
\end{abstract}

KEY WORDS ammonium chloride · antiseptic . cetylpyridinium chloride SARS-CoV-2

\section{INTRODUCTION}

The coronavirus family recently gained a new member in SARS-CoV-2 to go along with SARS-CoV and MERSCoV. Infection with SARS-CoV-2 causes COVID-19 which has rapidly become a pandemic (with at the time of writing millions infected and hundreds of thousands dead) requiring social distancing, leading to global shutdowns, resulting in a

Electronic supplementary material The online version of this article (https://doi.org/I 0. I007/s I I095-020-02842-8) contains supplementary material, which is available to authorized users.

Sean Ekins

sean@collaborationspharma.com

Leidos, Research Triangle Park, Durham, North Carolina, USA

2 Center for Computational Toxicology and Exposure, Office of Research and Development, U.S. Environmental Protection Agency (U.S. EPA), Research Triangle Park, Durham, North Carolina, USA

3 Laboratory for Molecular Modeling, UNC Eshelman School of Pharmacy, UNC Chapel Hill, Chapel Hill, North Carolina 27599, USA

4 Collaborations Pharmaceuticals, Inc., 840 Main Campus Drive, Lab 35I0, Raleigh, North Carolina 27606, USA

5 UNC Catalyst for Rare Diseases, Eshelman School of Pharmacy, UNC Chapel Hill, Chapel Hill, North Carolina 27599, USA recession, and pushing healthcare infrastructures to the breaking point. This pandemic is demanding an urgent response and we need to rapidly find treatments which can be accomplished by using existing drugs. Thus, drug repurposing for COVID-19 has garnered mainstream attention which did not occur in previous epidemics (1).

Initially the response from China and elsewhere was for scientists to look at compounds tested previously against SARS and MERS almost exclusively (2). Ritonavir/lopinavir, remdesivir (repurposed from Ebola and FDA emergency approved), chloroquine and hydroxychloroquine (both now FDA emergency approved, see Supplementary Material) are the most well-known compounds currently in clinical trials. Other drug repurposing efforts have used computational approaches such as docking or biological network mining to identify molecules as candidates for future testing (2-7) (Supplementary Material). To date there have been few large-scale high-throughput repurposing screens of antiviral inhibition described in the literature (8). These data as well as the earlier SARS and MERS data $(9,10)$ could ultimately be useful for machine learning models in order to predict new molecules from a much wider array of sources and select compounds to test in vitro and in vivo. However, there are only a small number of compounds to date $(\sim 100)$ with reported reliable in vitro data.

\section{Bibliometric Analysis Leads to Quaternary Ammonium Compounds}

An exhaustive bibliometric analysis of drug repurposing over the decades conducted by this team recently has described the many drugs that have been tested for other indications (11). This analysis highlighted chloroquine as one of the most repurposed approved drugs which has been tested against hundreds of diseases (11). Not surprisingly, chloroquine has also been identified by several groups (in China, South Korea and the USA, (4-7) to have micromolar activity against 
SARS-CoV-2 in vitro and along with the derivative hydroxychloroquine has even entered multiple clinical trials (Supplementary Material). The results have not suggested good efficacy as yet (12) from the limited clinical trial reports. This could be due to a number of reasons such as the metabolism and disposition of these drugs and the therapeutic window. We have now used the same text mining approach to focus solely on drugs that have been used in the treatment of coronaviruses (Supplementary Material, Table S1). This analysis identified ammonium chloride, which is commonly used as a treatment option for severe cases of metabolic alkalosis, as a drug of interest. Ammonium chloride is a quaternary ammonium compound that is known to also have antiviral activity $(13,14)$ against coronavirus (Supplementary Material) and has a mechanism of action such as raising the endocytic and lysosomal $\mathrm{pH}$, which it shares with chloroquine (15). Review of the text-mined literature also indicated a high-frequency of quaternary ammonium disinfectants as treatments for many viruses (Supplementary Material) (16,17), including coronaviruses: these act by deactivating the protective lipid coating that enveloped viruses like SARS-CoV-2 rely on. Quaternary ammonium compounds are widely recommended to kill viruses and there are over 350 products on EPA's List N: Disinfectants for use against SARS-CoV-2 (Supplementary Material. The disinfectant concentrations and contact times (associated with multiple viruses) for many of the disinfecting chemicals on the EPA list have been reported and $>140$ can deactivate the virus in just a few minutes (18).

\section{Cetylpyridinium Chloride and Miramistin}

This information led us on a larger search for quaternary ammonium compounds with activity against coronaviruses and possible identification of chemicals that have already been tested in the clinic and could be used as a potential treatment for COVID-19 (Table S2). One of the disinfectants that has been shown to be destructive to viruses (Supplementary Material) and widely used in personal care products is cetylpyridinium chloride (Table 1) $(19,20)$. This compound is found predominantly in mouthwashes and is listed by the FDA as Generally Regarded as Safe (GRAS) such that it is also being used as an antimicrobial agent for meat and poultry products (up to $1 \%$ ). Cetylpyridinium chloride has been used in multiple clinical trials (21), including as a treatment against respiratory infections (21) validating its use as an antiviral. Cetylpyridinium likely promotes virus inactivation by destroying the capsid as well as through its lysosomotropic action, which, as discussed above, is common for quaternary ammonium compounds. This raises the question as to whether some of the drugs identified with antiviral activity against SARSGoV-2 in vitro behave similarly, namely they may destroy the virus capsid as well as accumulating in the lysosome or endosomes and ultimately blocking viral entry. Additional published studies have suggested that this effect can be attenuated by the use of Cathepsin-L inhibitors (22). Another potential treatment candidate is miramistin (Table 1), a drug belonging to the group of cationic antiseptics, which is also a quaternary ammonium compound reported to have a wide array of biological activities including antiviral against HIV (23). Miramistin is approved as broad-spectrum anti-infective agent in Russia (24), but it does not appear to have been adopted in the rest of the world. There are numerous FDA approved drugs that have a quaternary nitrogen, and it is possible these could also have a similar broad antiseptic effect.

The current COVID-19 pandemic is sweeping the globe at an unprecedented rate fanned by our global connectivity. To date it has spurred drug discovery activity (albeit considerably impacted by research laboratory shutdowns) and much interest in drug repurposing in the hope of delivering effective drugs to the patient faster. The success of this approach will take time to validate as we await clinical trial data from all of the earliest compounds in the clinic. We hypothesized that text mining of the available published literature in PubMed would enable us to identify compounds faster that have been tested against other coronaviruses, but which were not currently being evaluated clinically. Our studies guided by this approach suggest that while many drugs have been tested, the lysosomotropic agent ammonium chloride and quaternary ammonium compounds such as cetylpyridinium chloride and miramistin may produce the desired antiviral effect but have not as yet been tested against SARS-CoV-2 in vitro or in clinical trials. We have briefly described this data mining process that identified these classes of compounds of interest and provide our analysis for others to expand up on

Table I Quaternary ammonium compounds with known coronavirus activity

\begin{tabular}{|c|c|c|c|c|}
\hline Molecule & Antiviral activity & Mechanism & FDA approved & Uses \\
\hline Ammonium Chloride & Murine coronavirus, hepatitis C, & Lysosomotropic & Yes & Various uses including metabolic acidosis. \\
\hline Cetylpyridinium chloride & Influenza, hepatitis B, poliovirus I & $\begin{array}{l}\text { Targets capsid and is } \\
\text { lysosomotropic }\end{array}$ & Yes, GRAS & $\begin{array}{l}\text { Antiseptic, mouthwash, cough lozenges, } \\
\text { personal care products, cleaning agents etc. }\end{array}$ \\
\hline Miramistin & HIV, influenza, herpes, SARS & $\begin{array}{l}\text { Immunostimulating, } \\
\text { targets capsid and is } \\
\text { lysosomotropic }\end{array}$ & $\begin{array}{l}\text { No, but is approved } \\
\text { in Russia }\end{array}$ & Antiseptic \\
\hline
\end{tabular}


(Supplementary Material, Table S1). Limitations of the text mining approach are that at the time of writing there had only been reports of approximately 450 molecules associated with other coronaviruses and many of these could likely be discounted due to no reported antiviral activity, toxicity and perhaps most important, the lack of FDA approved status.

\section{SUMMARY}

We propose that in particular, cetylpyridinium chloride is a simple molecule that is cheap, safe, clinically approved, widely accessible in hospitals and the consumer sector and which could enter clinical trials immediately. If reported to have activity in vitro against SARS-CoV-2 subsequent delivery in the form of a mouthwash or nasal spray containing this compound may be an effective way both to combat the virus at its point of entry and reduce SARS-CoV-2 transmission. Similarly, this compound could be added to shampoo and body cleansers so that one could effectively bathe in low concentrations of this compound to destroy shed coronavirus. Cetylpyridinium chloride and many other quaternary ammonium compounds have already demonstrated their antiviral activity against a wide array of related coronaviruses as disinfectants and antiseptics, therefore they represent especially low hanging fruit for testing in humans. Due to their reported mechanisms they may also have much broader activity against viruses which could be useful to address future enveloped viruses. Certainly, additional studies may be warranted to assess potential drug-drug or drug-transporter interactions. This work may also point to other related compounds that could be utilized, or at least enable the generation of new antiviral compounds that leverage the quaternary ammonium substructural fragment as a potential warhead. As simple as it sounds, it is entirely possible that we should be looking in our bathroom cupboards, for potential remedies against COVID19.

\section{ACKNOWLEDGMENTS AND DISCLOSURES}

This work has been reviewed at the US EPA and has been approved for publication. The views expressed in this publication are those of the authors and do not necessarily represent the views or policies of the United States Environment Protection Agency. Reference to commercial products or services does not constitute endorsement.

\section{FUNDING}

We kindly acknowledge NIH funding: R44GM122196-02A1 from NIGMS, R21TR001718 from NCATS and R43AT010585-01S1 from NCCAM (PI - Sean Ekins) and 1OT2TR002514-01 (Pi - Alexander Tropsha).

\section{COMPLIANCE WITH ETHICAL STANDARDS}

Conflict of Interest SE is CEO and owner of Collaborations Pharmaceuticals. All other co-authors have no conflicts of interest.

\section{REFERENCES}

1. Gates B. Responding to Covid-19 - a once-in-a-century pandemic? N Engl J Med. 2020;382:1677-9.

2. Ekins S, Mottin M, Ramos PRPS, Sousa BKP, Neves BJ, Foil DH, Zorn KM, Braga RC, Coffee M, Southan C, Puhl AC, Andrade CH. Déjà vu: Stimulating Open Drug Discovery for SARS-CoV-2. Drug Discov Today. 2020; Apr 19:S1359-6446(20)30145-8. https://doi.org/10.1016/j.drudis.2020.03.019.

3. Stebbing J, Phelan A, Griffin I, Tucker C, Oechsle O, Smith D, et al. COVID-19: combining antiviral and anti-inflammatory treatments. Lancet Infect Dis. 2020;20(4):400-2.

4. Jeon S, Ko M, Lee J, Choi I, Byun SY, Park S, Shum D, Kim S. Identification of antiviral drug candidates against SARS-CoV-2 from FDA-approved drugs. Available from: https://www.biorxiv. org/content/10.1101/2020.03.20.999730vl.

5. Jin Z, Du X, Xu Y, Deng Y, Liu M, Zhao Y, Zhang B, Li X, Zhang L, Peng C, Duan Y, Yu J, Wang L, Yang K, liu F, Jiang R, Yang X, You T, Liu X, Yang X, Bai F, Liu H, Liu X, Guddat LW, Xu W, Xiao G, Qin C, Shi Z, Jiang HY, Rao Z, yang H. Structure of Mpro from 1 COVID-19 virus and discovery of its inhibitors. Available from: https://www.biorxiv.org/content/10.1101/2020. 02.26.964882v2.

6. Liu J, Cao R, Xu M, Wang X, Zhang H, Hu H, et al. Hydroxychloroquine, a less toxic derivative of chloroquine, is effective in inhibiting SARS-CoV-2 infection in vitro. Cell Discov. 2020;6:16.

7. Wang M, Cao R, Zhang L, Yang X, Liu J, Xu M, et al. Remdesivir and chloroquine effectively inhibit the recently emerged novel coronavirus (2019-nCoV) in vitro. Cell Res. 2020;30(3):269-71.

8. Riva L, Yuan S, Yin X, Martin-Sancho L, Matsunaga N, Burgstaller-Muehlbacher S, Pache L, De Jesus PP, Hull MV, Chang M, Chan JF-W, Cao J, Poon VK-M, Herbert K, Nguyen T-T, Pu Y, Nguyen C, Rubanov A, Martinez-Sobrido L, Liu W-C, Miorin L, White KM, Johnson JR, Benner C, Sun R, Schultz PG, Su A, Garcia-Sastre A, Chatterjee AK, Yuen K-Y, Chanda SK. A Large-scale Drug Repositioning Survey for SARS-CoV-2 Antivirals. bioRxiv. 2020:2020.2004.2016.044016.

9. de Wilde AH, Jochmans D, Posthuma CC, Zevenhoven-Dobbe JC, van Nieuwkoop S, Bestebroer TM, et al. Screening of an FDAapproved compound library identifies four small-molecule inhibitors of Middle East respiratory syndrome coronavirus replication in cell culture. Antimicrob Agents Chemother. 2014;58(8):4875-84.

10. Dyall J, Coleman CM, Hart BJ, Venkataraman T, Holbrook MR, Kindrachuk J, et al. Repurposing of clinically developed drugs for treatment of Middle East respiratory syndrome coronavirus infection. Antimicrob Agents Chemother. 2014;58(8):4885-93.

11. Baker NC, Ekins S, Williams AJ, Tropsha A. A bibliometric review of drug repurposing. Drug Discov Today. 2018;23(3):661-72.

12. Borba MGS, Val FFA, Sampaio VS, Alexandre MAA, Melo GC, Brito M, Mourao MPG, Brito-Sousa JD, Baia-da-Silva D, Guerra MVF, Hajjar LA, Pinto RC, Balieiro AAS, Pacheco AGF, Santos JDO, Jr., Naveca FG, Xavier MS, Siqueira AM, Schwarzbold A, Croda J, Nogueira ML, Romero GAS, Bassat Q, Fontes CJ, Albuquerque BC, Daniel-Ribeiro CT, Monteiro WM, Lacerda MVG, CloroCovid T. Effect of high vs low doses of chloroquine 
diphosphate as adjunctive therapy for patients hospitalized with severe acute respiratory syndrome coronavirus 2 (SARS-CoV-2) Infection: A Randomized Clinical Trial. JAMA Netw Open. 2020;3(4):e208857.

13. Mizzen L, Hilton A, Cheley S, Anderson R. Attenuation of murine coronavirus infection by ammonium chloride. Virology. 1985; 142(2):378-88.

14. Hoffmann MM, Kleine-Weber H, Kruger N, Muller M, Drosten C, Pohlmann S. The novel coronavirus 2019 (2019-nCoV) uses the SARS-coronavirus receptor 2 ACE2 and the cellular protease TMPRSS2 for entry into target cells. Available from: https:// www.biorxiv.org/content/10.1101/2020.01.31.929042v1.full.pdf.

15. Ashfaq UA, Javed T, Rehman S, Nawaz Z, Riazuddin S. Lysosomotropic agents as HCV entry inhibitors. Virol J. 201 1;8: 163.

16. Rabenau HF, Kampf G, Cinatl J, Doerr HW. Efficacy of various disinfectants against SARS coronavirus. J Hosp Infect. 2005;61(2): 107-11.

17. Dellanno C, Vega Q Boesenberg D. The antiviral action of common household disinfectants and antiseptics against murine hepatitis virus, a potential surrogate for SARS coronavirus. Am J Infect Control. 2009;37(8):649-52.

18. Anon. Disinfectant Concentrations and Contact Times for EPA's List of Products Effective against Novel Coronavirus SARS-CoV-2, the Cause of COVID-19. 20201 April. Available from: https:// www.ecri.org/components/HDJournal/Pages/DisinfectantConcentrations-for-EPA-list-N-COVID-19.aspx?tab=2 .
19. Zhu DM, Evans RK. Molecular mechanism and thermodynamics study of plasmid DNA and cationic surfactants interactions. Langmuir. 2006;22(8):3735-43.

20. Fromm-Dornieden C, Rembe JD, Schafer N, Bohm J, Stuermer EK. Cetylpyridinium chloride and miramistin as antiseptic substances in chronic wound management - prospects and limitations. J Med Microbiol. 2015;64(Pt 4):407-14.

21. Mukherjee PK, Esper F, Buchheit K, Arters K, Adkins I, Ghannoum MA, et al. Randomized, double-blind, placebocontrolled clinical trial to assess the safety and effectiveness of a novel dual-action oral topical formulation against upper respiratory infections. BMC Infect Dis. 2017;17(1):74.

22. Simmons G, Gosalia DN, Rennekamp AJ, Reeves JD, Diamond SL, Bates P. Inhibitors of cathepsin L prevent severe acute respiratory syndrome coronavirus entry. Proc Natl Acad Sci U S A. 2005;102(33): 11876-81.

23. Krivorutchenko Iu L. KrivosheinIuS, Marennikova SS, Stepanova LG, Nosik DN, Kalnina LB, Rud'ko AP. [study of the anti-HIV activity of miramistin]. Vopr Virusol. 1994;39(6):267-9.

24. Agafonov AP, Skarnovich MO, Petrishchenko VA, Shishkina LN, Sergeev AN, Svistov VV, et al. In vitro study of antiviral activity of Myramistin against subtypes H3N2 and $\mathrm{H} 5 \mathrm{~N} 1$ of influenza virus. Antibiot Khimioter. 2005;50(12):9-11.

Publisher's Note Springer Nature remains neutral with regard to jurisdictional claims in published maps and institutional affiliations. 